\title{
Wildland Fire Behaviour Case Studies and Fuel Models for Landscape-Scale Fire Modeling
}

\author{
Paul-Antoine Santoni, Jean-Baptiste Filippi, Jacques-Henri Balbi, and Frédéric Bosseur
}

SPE UMR 6134 CNRS, University of Corsica, Campus Grimaldi BP 52, 20250 Corte, France

Correspondence should be addressed to Paul-Antoine Santoni, santoni@univ-corse.fr

Received 6 March 2011; Accepted 18 July 2011

Academic Editor: D Morvan

Copyright () 2011 Paul-Antoine Santoni et al. This is an open access article distributed under the Creative Commons Attribution License, which permits unrestricted use, distribution, and reproduction in any medium, provided the original work is properly cited.

\begin{abstract}
This work presents the extension of a physical model for the spreading of surface fire at landscape scale. In previous work, the model was validated at laboratory scale for fire spreading across litters. The model was then modified to consider the structure of actual vegetation and was included in the wildland fire calculation system Forefire that allows converting the two-dimensional model of fire spread to three dimensions, taking into account spatial information. Two wildland fire behavior case studies were elaborated and used as a basis to test the simulator. Both fires were reconstructed, paying attention to the vegetation mapping, fire history, and meteorological data. The local calibration of the simulator required the development of appropriate fuel models for shrubland vegetation (maquis) for use with the model of fire spread. This study showed the capabilities of the simulator during the typical drought season characterizing the Mediterranean climate when most wildfires occur.
\end{abstract}

\section{Introduction}

The ability of the forest fire community in modelling and simulating forest fire spread [1-4], as well as developing management approaches and techniques [5], has increased significantly in recent years. Modelling has become an essential tool in forest fire research and becomes a crucial instrument in the studies of wildland-urban interface fires [1], fire mitigation, and risk mapping [5]. Wildfires are driven by complex physical and chemical processes, operating on vastly different scales ranging from micrometers to kilometers. Their interactions depend on coupling between nonlinear phenomena such as turbulence in the lower part of the atmospheric boundary layer, topography, vegetation, and fire itself (chemical reactions, radiation heat transfer, and degradation of the vegetation). Different reviews of fire spread models have been conducted these last ten years $[6,7]$. Depending on the authors, wildland fire mathematical models may be classified according to the nature of the equations (physical, quasiphysical, quasiempirical, and empirical) or according to the physical system modeled (surface fire models, crown fire models, spotting models, and ground fire models). With regard to the first classification, the simplest models are the statistical ones, which make no attempt to involve physical mechanisms [8]. Empirical models [9] are based upon the conservation of energy, but they do not distinguish the mode of heat transfer. Finally, physical models differentiate the various kinds of heat transfer in order to predict fire behaviour [10]. Among them, multiphase modeling [4] and coupled fire-fuel-atmosphere models $[1,11]$ represent the most complete approach developed so far. Whatever the classification, there is a general agreement on the fact that simple models have to be used if one wants to provide real-time operational tools. Conversely, multidimensional numerical fluid-dynamical wildfire simulation models must be used to study the behavior of wildfire and wildlandurban interface fires. However, these last models require computational resources that preclude real-time forecasts [1]. The computational cost of physics-based wildland fire modeling limits the application of the approach to modeling wildfire behaviour within a certain scale range. On another hand, quasiempirical and empirical model may be very efficient for fuel and environmental conditions comparable to those of test-fires, but the absence of a real physical description makes them inapplicable to other situations. The dilemma is whether one wants to simulate wildfire phenomenon accurately or quickly. 
The aim of the present paper is to extend at landscape scale a physical model of surface fire [3]. Up to now, the model has been tested only at laboratory scale against experiments for which fuel beds of pine needles or straw were used [12]. Although pine litter presents a clear fire hazard in pine forests by providing a continuous fuel matrix across the forest floor, fire hazard also corresponds clearly to grassfires, fires in shrubland and forest fires. Our model of fire spread was thus modified to take into account the structure of the actual vegetation. Particular attention was paid to intermixed live and dead vegetation found in the Mediterranean maquis. Fire behavior fuel models were developed for some Mediterranean vegetation types in order to match the requirements of the modified model of surface fire. The fire model was included in the wildland fire calculation system Forefire [13]. Forefire allows conversion of the two-dimensional model $(x-z)$ to three dimensions $(x-y-z)$ and then simulating the propagation of the fire perimeter across a modeled landscape, taking into account spatial information. Two wildfire case studies have been reconstructed and used to test the simulation model. Wildland fires are very difficult, if not impossible, to study with full-scale repeatable experiments in the field [14] due to their expense, safety implications, and variations in atmosphere, terrain, and fuel conditions. However, although basic research on combustion is essential to a full understanding of fire behavior, such research would not be very useful without actual field experience gained and case study documentation. Wildfire case studies are invaluable in providing fire behavior data for developing and evaluating fire behavior models [15]. The contribution of the present work is the development of a wildfire calculation system based on a physical model of fire spread that satisfies two contradictory properties: to be as complete as possible with regard to the equations that govern fires and to be as simple as possible to predict fire behavior faster than real time. The model distinguishes the mode of heat transfer and avoids the complexity of the chemical aspect related to combustion. It is, thus, able to provide information on physical quantities like radiant heat flux [12]. Conversely, most commonly used operational models for wildland fire spread rely on empirically derived relations to predict the spread rate of a wildland fire across landscapes. In the United States, FARSITE [16] is based on the quasiempirical spread model of Rothermel [9]. In Australia, SiroFire [17] uses McArthur's fire spread models for grass [8] and forest [18] as well as the recommended replacement grassland model [19]. The Canadian Wildland Fire Growth Model, Prometheus [20], is based on the Canadian Fire Behaviour Prediction System [21] and uses the wavelet propagation algorithms of Richards [22]. The approach presented in the current paper is not a coupled atmosphere-wildland fire model. We use realistic precalculated wind field data as input. The impact of the fire on the atmosphere and the subsequent feedback of these fire-induced winds on fire behavior are not simulated.

\section{Fire Model and Fire Simulator Overviews}

2.1. Fire Model. The aim is to provide a model of surface fire that will form the core of a simulation tool for fire fighters.

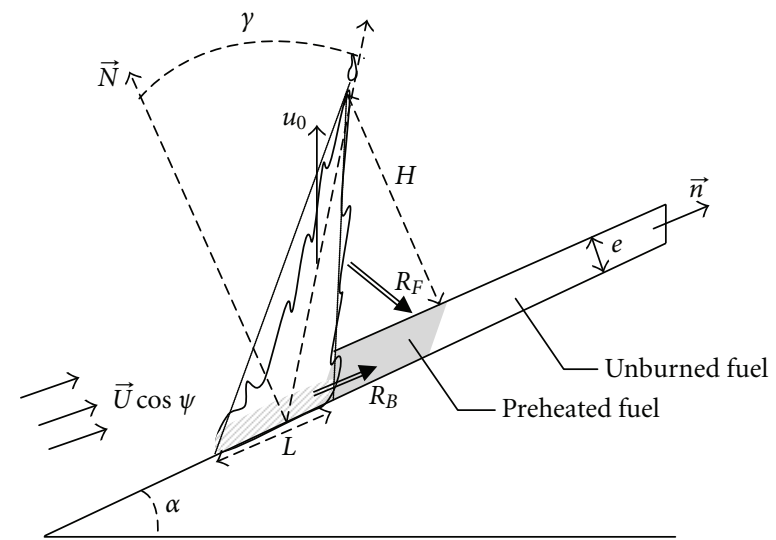

FIGURE 1: Flame profile along the normal direction to the fire front.

The model is derived from a simplified modeling of the transport phenomena governing the fire $[3,12]$. It is physical, because in addition to rate of spread, it provides also the main global physical quantity related to the fire front such as radiant heat flux. Its computational time must be low to be usable under real time conditions for the simulation of actual wildland fires. Its accuracy must be reasonably good. The main calculation steps leading to the model equations are provided in appendix. The appendix describes the first version of the model elaborated at laboratory scale for dead fuel. The interested reader is referred to $[3,12]$ for more details on this model. In this section, we outline these equations, and we propose some modification to simulate actual vegetation. The main equations are for the flame tilt angle $\gamma$ and for the rate of spread $R \cdot \gamma$ and $R$ are, respectively, given by

$$
\begin{gathered}
\tan \gamma=\tan \alpha \cos \phi+\frac{U}{u_{0}} \cos \psi, \\
R=R_{B}+R_{F}, \\
R_{B}=\frac{D_{d}}{\sigma_{d}} \frac{B T_{B}^{4}}{\left(c_{p d} \Delta T+m_{d} \Delta h\right)} \\
R_{F}=A R \frac{1+\sin \gamma-\cos \gamma}{1+(R \cos \gamma) / r_{0}} .
\end{gathered}
$$

In (1), $\alpha$ represents the slope angle, $\phi$ is the angle between the unit vector, normal to the fire front and the unit ground slope vector, and $\psi$ is the angle between the unit vector normal to the fire front and the wind velocity vector, $\vec{U} . U$ is the value of the wind velocity. In (2), $R_{B}$ and $R_{F}$ represent, respectively, the contributions to rate of spread, of the radiation due to embers, and radiation due to the flame when it is tilted under wind and/or slope condition (Figure 1).

In (2a), $D_{d}$ is the depth of the vegetation, $\sigma_{d}$ is the fuel load, $B$ is the Stefan-Boltzman constant $(5.67 \times$ $\left.10^{-8} \mathrm{~W} /\left(\mathrm{m}^{2} \mathrm{~K}^{4}\right)\right), T_{f}$ is the temperature in the burning fuel, $c_{p d}$ is the specific heat of the fuel, $\Delta T=T_{i g}-T_{a}$, where $T_{i g}$ is the temperature of ignition and $T_{a}$ is the ambient temperature, $m_{d}$ is the fuel moisture content on dry basis, 
and $\Delta h$ is the latent heat of vaporization of water $(\Delta h=$ $\left.2.25 \times 10^{3} \mathrm{~kJ} / \mathrm{kg}\right)$. In (1) and (2b), the terms $u_{0}, r_{0}$, and $A$ are given by

$$
\begin{aligned}
& u_{0}=v u_{00}, \\
& r_{0}=s_{d} r_{00}, \\
& A=v A_{0},
\end{aligned}
$$

where

$$
\begin{gathered}
v=\inf \left(\frac{s_{d} D_{d} \beta_{d}}{4,1}\right), \\
u_{00}=8 \frac{\left(s_{t}+1\right)}{\tau_{0} / \rho_{d}} \frac{T_{f}}{\rho_{a} T_{a}}, \\
A_{0}=\frac{\chi_{0} \Delta H}{4\left(c_{p d} \Delta T+m_{d} \Delta h\right)}, \\
T_{f}=T_{a}+\frac{\left(1-\chi_{0}\right) \Delta H}{\left(s_{t}+1\right) c_{p a}},
\end{gathered}
$$

$u_{0}$ stands for the upward velocity of the combustion gases under no slope. It is given by (3a), (4a), and (4b) in which $s_{d}$ is the surface to volume ratio of the fuel, $\beta_{d}$ is the packing ratio of the fuel, $s_{t}$ is stoichiometric mass-based air/fuel ratio for the complete combustion of pyrolisis gases in air $\left(s_{t}=\right.$ 8.3), $\tau_{0}$ is the empirical constant provided by Anderson [23] for the residence time of fire, $\rho_{d}$ is the density of the fuel and $\rho_{a}$ is the density of ambient air. In (4c), $\chi_{0}$ represents the radiant fraction of the rate of heat release within the flame. The model assumes that the radiant heat transfer fraction decreases when the volume to surface ratio of the flame increases and $r_{00}$ is a model parameter used to establish this relationship [12]. In (4d), $\Delta H$ is the net heat of combustion of the combustible gases and $c_{p g}$ is the specific heat content of air at $1273 \mathrm{~K}\left(c_{p a}=1173 \mathrm{~J} \cdot \mathrm{kg}^{-1} \cdot \mathrm{K}^{-1}\right)$. The values of the model parameters are $\tau_{0}=75590 \mathrm{~s} \cdot \mathrm{m}^{-1}, \chi_{0}=0.3$ and $r_{00}=2.5 \times 10^{-5} \mathrm{~m} \cdot \mathrm{s}^{-1}$. The fuel parameters are given in the section devoted to the presentation of the fire behaviour fuel model.

As mentioned in Section 1, we recall that our aim is to extend at landscape scale this model of surface fire. Hence, the simple structure of the model was kept, considering that shrubland fires are surface fires. Shrubland include both dead and live vegetations that must be considered in the thermal balance. Two hypotheses are thus formulated. We first assume that thin dead fuels (1-h) are mainly responsible of the fire spread considering that live fuels and coarse dead fuels (greater than 10-h) are partly desiccated within the flame and not only ahead of the fire front. We assume also that ahead of the fire front, the heat flux impinges both dead and live fuels in proportion to their leaf area index. With these hypotheses, (2), (4c), and (4d) become

$$
\begin{gathered}
R=R_{B} \times\left(\frac{S_{d}}{S_{d}+S_{l}}\right)^{2}+R_{F}, \\
A_{0}=\frac{\chi_{0} \Delta H(1-\xi)}{4\left(c_{p d} \Delta T+m_{d} \Delta h\right)}, \\
T_{f}=T_{a}+\frac{\left(1-\chi_{0}\right) \Delta H(1-\xi)}{\left(s_{t}+1\right) c_{p a}},
\end{gathered}
$$

with

$$
\begin{gathered}
S_{d}=s_{d} D_{d} \beta_{d}, \\
S_{l}=s_{l} D_{l} \beta_{l}, \\
\xi=\left(m_{l}-m_{d}\right) \frac{S_{l}}{S_{d}} \frac{\Delta h}{\Delta H} .
\end{gathered}
$$

In these relations, the subscripts $d$ and $l$ are, respectively, for 1 -h dead and thin live fuels, while $s, e, \beta$, and $m$ remain as defined in this section.

2.2. Fire Simulator. The model of fire spread is bidimensional, since it provides the flame height (not detailed here but given in [12]) and the forward rate of spread. It is, however, necessary to develop a method of converting the forward spread model into a two-dimensional one that could spread the entire perimeter across a landscape. This involves two distinct processes: first, representing the fire perimeter in a manner suitable for simulation, and second, propagating that perimeter in a manner suitable for the perimeter's representation. Both processes are carried out by Forefire [13]. The Forefire simulation code is based on a discrete event simulation (DEVS) [24] formalization of a front tracking method. In the front tracking method, the fire line is decomposed into a set of connected points, or markers, like in FARSITE [16]. Each marker is a DEVS [24] atomic model that has a specific propagation direction and speed, as shown in Figure 2. The speed at which the marker is traveling along its propagation vector is given by the rate of spread of the fire model $(2 \prime)$. The direction of the propagation vector is given by the bisector of the angle formed by the marker with its left and right neighbor's (see Figure 2). Markers are redistributed along the front if separated by more than the resolution distance $\Delta r$ and removed if separated by less than $\Delta r / 4$. A fire line is defined as a full set of interconnected markers. If two points of different fire lines are separated by less than $\Delta r / 4$, the two fronts are merged. The integration of a marker advance is performed in a discrete event manner, with no global time step but specific activation time for markers. Every marker is always advancing by the same distance $\Delta q$, estimated from the propagation speed when the marker would travel this distance. The timed activated events are placed in a sorted event list, and the simulation is performed by activating the most imminent event. The method has been selected because of its computational efficiency and its ability to simulate the propagation of an interface at high resolution 


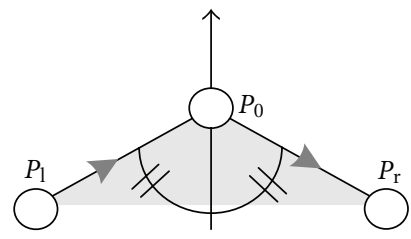

(a)

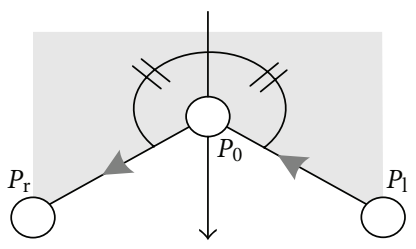

(b)
Figure 2: Front tracking and markers. Circles represent markers along the fire line. Arrows show the propagation vector (bisector of the local angle at the marker $P_{0}$ between the left point $P_{1}$ and the right point, $P_{\mathrm{r}}$ ). The grey area represents the burned fuel.

(submeter) needed to take into account different vegetation, roads, houses, and fire breaks over a large area typical of wildfires (hundreds of square kilometers). Concerning ignition, the fire simulator necessitates defining a burning area (usually a triangle) since it follows a Lagrangian schema. The size of each segment of this polygon is given by the resolution of the numerical perimeter of the simulation. Usually, this resolution (quantum distance $\Delta r$ ) is 8 meters. Thus, the initial contour is an 8 meters sided equilateral triangle. Decreasing the quantum size does not influence the simulation results but increases the calculation time.

\section{Case Studies}

This section summarizes the findings from the case studies of Favone fire and Suartone fire that occurred in South Corsica coastal region. In the last fifty years, this area was submitted to several catastrophic wildfires which lasted several days and burned thousands hectares of shrub. Most of them occurred in summer under western windy condition, high ambient temperature (greater than $30^{\circ}$ ), low relative humidity (lower than 30\%), low fuel moisture content, and drought conditions. The case studies were selected in this area in order to get simultaneously some of those conditions for which high-intensity fires occurred. Although many of the environmental factors affecting severe fire occurrence have already been recognized [25], it has been observed that there is not some constant prevailing. There are, rather than that, mixes of several danger variables, that together produce conditions for a major fire to occur. Our aim was to reconstruct wildfires representative of weather and fuel state conditions encountered in severe fires. For both cases, we detail the chronology and behavior of the fire, the environmental conditions (topography and fuel mapping, meteorological data) as well as the suppression activities.

\subsection{Favone Fire Case Study}

3.1.1. Chronology and Behavior. This (human-caused) fire occurred in South-East Corsica in July 08, 2009 (Figure 3) near the village of Favone (ignition point: lat. $41^{\circ} 45^{\prime} 57.08^{\prime \prime}$, long. $09^{\circ} 23^{\prime} 44.84^{\prime \prime}, 33 \mathrm{~m}$ a.s.l.), where about 30 ha were burned. The fire was detected at about 3:00 p.m. in a place (Figure 4(a)), where fuel load was reduced by mechanical treatment. Logs were burned and smoldered causing

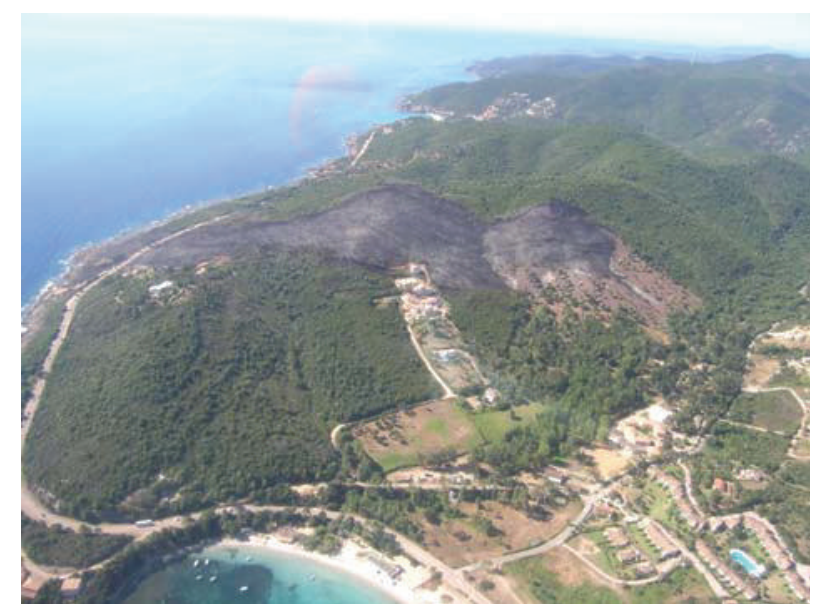

FIGURE 3: Fire perimeter for the case study of Favone fire (courtesy of South-Corsica firefighters).

the Favone fire. The fire spread quickly, moving uphill (Figure 4(b)) and then shifted on the left towards the east driven by a western south-western wind of about $18 \mathrm{~km} / \mathrm{h}$ in average. A tourist detected the fire and called firefighters. The first crews happened to arrive on scene at 3:05 p.m. within 5 minutes of the fire's origin. The fire threatened some residential and resort areas on the left flank. Three crews (each crew composed of a pumper truck and men) were deployed to protect these residential and resort areas and to constrain the fire on its left flank. The terrain and fire intensity did not allow a direct suppression attack on the head of fire. At first, aerial resources (four air tankers) worked on the left flank to protect the residential and resort areas and to allow firefighters to be safely deployed. Then, aerial resources worked on the right flank. The idea was to push the fire towards the sea. The fire jumped over the road at 4:00 pm and reached the sea at about 4:15 pm. It was contained at this time by 10 crews deployed to extinguish the edges of the fire front. The fire was mopped up and declared out at 7:00 pm. The fire rate of spread was about $920 \mathrm{~m} / \mathrm{h}$ between points $A$ and $B$ under upslope condition (see Figure 5) and about $666 \mathrm{~m} / \mathrm{h}$ between points B and D under downslope condition.

3.1.2. Site Description. The site is located near the sea. It is slightly hilly with two hills along the path of the fire that do not exceed an altitude of $100 \mathrm{~m}$ (Figure 5). The area is characterized by the typical subarid Mediterranean climate, with a remarkable water deficit from May through September and most of the annual rainfall amount occurring in fall and winter. The burned area was composed of three vegetation types (Figure 5): a small part of the area was a woodland of Quercus suber (cork-oak) near the ignition point (9ha). It is referred to as Oakland 1 in the following. Near the road and the beach (end of the fire, point D in Figure 5), the area was covered by a low typical shrubland Mediterranean vegetation, with plant height of about $1.8 \mathrm{~m}$. This type of vegetation is a Mixture of grass and shrub, up to about 90 percent shrub coverage and 50 percent grass coverage below 


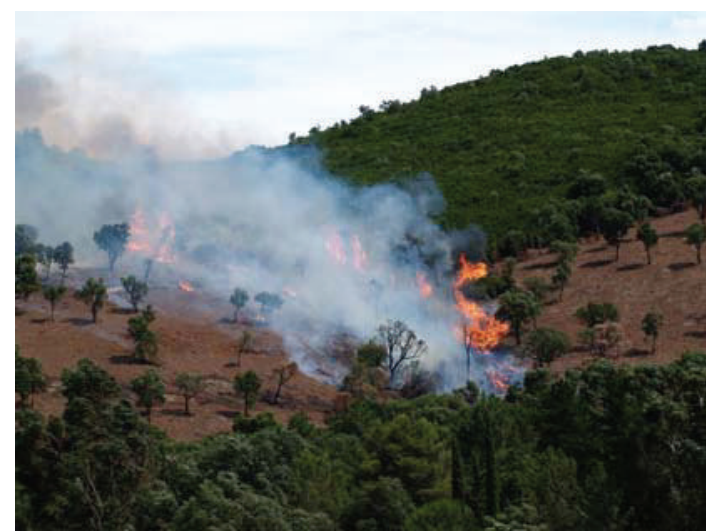

(a)

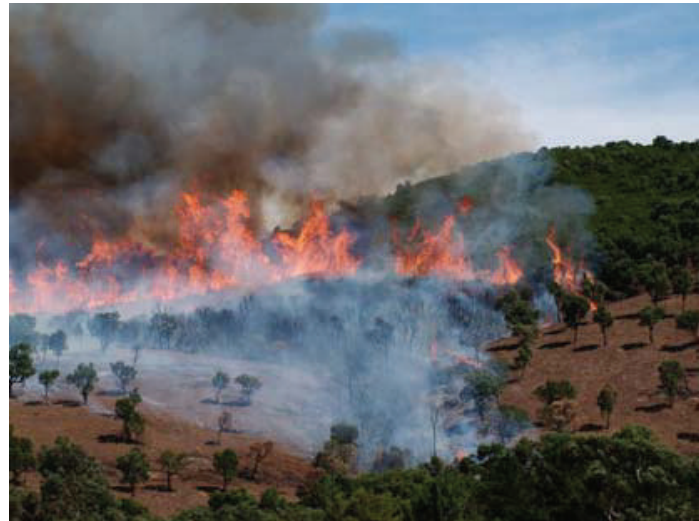

(b)

FIgURE 4: Ignition point and subsequent spreading.

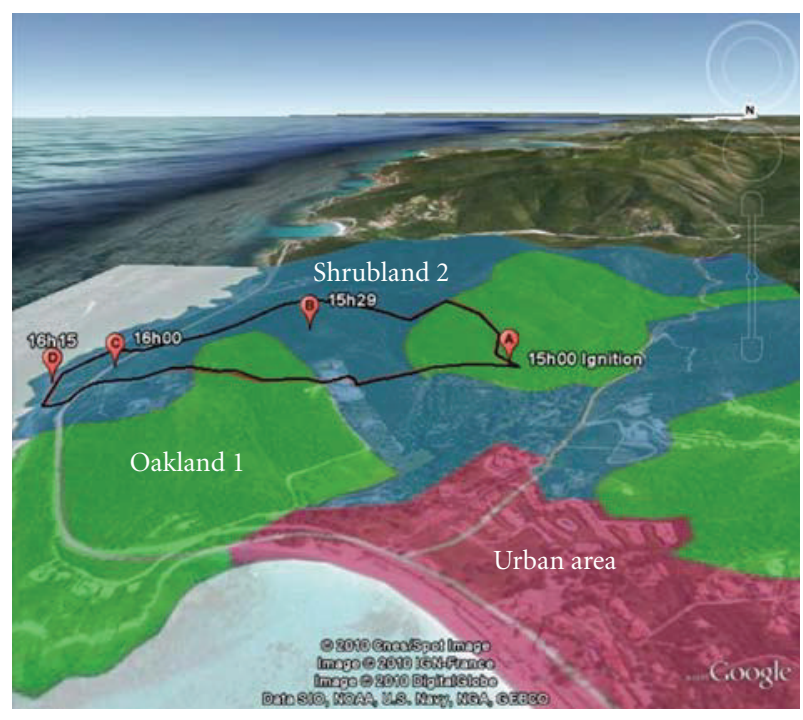

FIgURE 5: Topography, fire perimeter (in black) and vegetation types as defined in Table 1 for the case study of Favone fire.

the shrub. Dominant species included Erica arborea (60\%), Phyllirea angustifolia (15\%), Myrtus communis (15\%), and other species in fewer amounts. This vegetation type is not represented in Figure 5, since it represent a negligible part of the burned area (less than $1 \mathrm{ha}$ ). The rest and main part of the burned area was covered by a high typical shrubland Mediterranean vegetation (20 ha), with plant height ranging from 2 to $4 \mathrm{~m}$ and a coverage of 100\%. Quercus suber were scarcely present in this area. This type of vegetation is referred as Shrubland 2 in the following. There is no grass but a heavy litter of leaves of Arbutus unedo and Quercus suber. Dominant species included Arbutus unedo (50\%), Erica arborea (30\%), Pistacia lentiscus (10\%), and Quercus suber $(10 \%)$.

3.1.3. Environmental Conditions. Two regimes for wind speed and direction prevail in this area. The first one which is the most frequent is an easterly regime due to a sea breeze effect. It is especially present during daytime in the eastern façade of Corsica. The second one is a westerly regime due to large-scale atmospheric circulation. It takes place mainly during the night and after 4:00 pm when the sea breeze effects cease. The prevailing winds directions during which intense fire occur at the sites are typically west and southwest. It was the case for the Favone fire for which wind velocities varied between 5 and $7 \mathrm{~m} / \mathrm{s}$ and wind direction ranged from $240^{\circ}$ to $270^{\circ}$. Air temperatures varied from $25^{\circ} \mathrm{C}$ to $27^{\circ} \mathrm{C}$ during the fire, and relative humidity of air was between $41 \%$ and $46 \%$.

3.2. Suartone Fire Case Study. This site is about $30 \mathrm{~km}$ from Favone. Hence, the general description and environmental conditions provided in the previous section are similar. Only the local variation in vegetation and change in meteorological conditions the day of the fire are described in this section.

3.2.1. Chronology and Behavior. This fire occurred in SouthEast Corsica in July 28, 2003 (Figure 6) near the village of Suartone (ignition point: lat. $41^{\circ} 28^{\prime} 21.93^{\prime \prime}$, long. $9^{\circ} 13^{\prime} 30.48^{\prime \prime}, 40 \mathrm{~m}$ a.s.l.) where about 456 ha were burned. The fire was detected at 3:00 p.m. The first crew (pumper truck and men) happened to arrive on scene at 3:15 p.m. within 15 minutes of the fire's origin. The fire was spreading moderately in an area surrounded by shrubs on the left side of the road. Firefighters could not get near the fire and were too far away to drop water with their water cannon. Then, five more crews arrived on scene. The terrain and fire intensity did not allow the direct suppression attack on the head of fire. All crews were positioned on the road trying to extinguish the fire from their position. Suddenly, due to a local change in wind direction the fire jumped over the road. The right flank of the fire front was about 350-400 m. It became the fire head that accelerated both driven by a western wind of about $30 \mathrm{~km} / \mathrm{h}$ in average and upslope effect. Then, nearing the village of Suartone the rate of spread of the fire decreased. Aerial resources arrived and dropped water on both flanks of the fire and constrained it. The fire ended when 


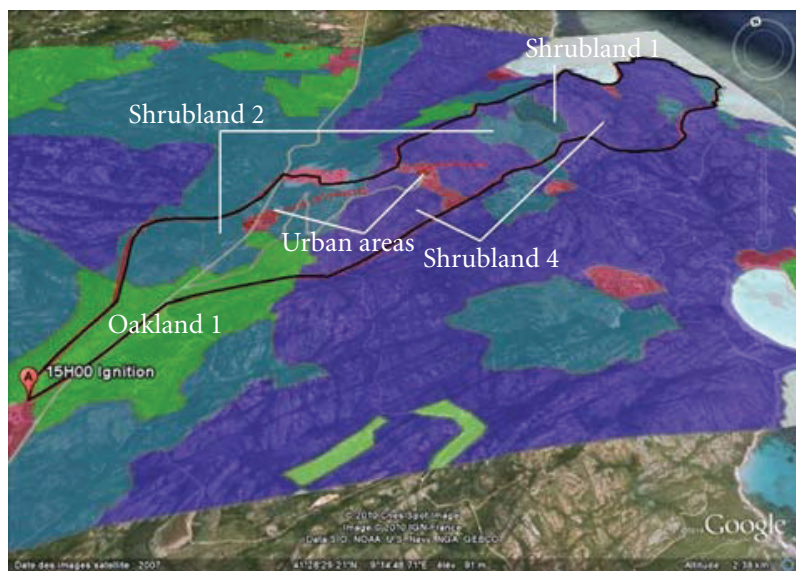

FIGURE 6: Topography, fire perimeter (in black) and vegetation type as defined in Table 1 for the case study of Suartone fire.

it reached the sea. It was mopped up at 7:00 pm and declared out in the night. The mean spread rate of the fire front between ignition and arrival at the sea was about $1440 \mathrm{~m} / \mathrm{h}$. Intermediate velocity was difficult to calculate due to few observations on scene.

3.2.2. Site Description. The site is located near the sea. Ignition occurred at the bottom of a canyon (Figure 6). Then, when the fire jumped over the road, it spread on a hilly area with four hills along the path of fire that do not exceed an altitude of $200 \mathrm{~m}$. The burned area was composed of four vegetation types (Figure 6). But two types of vegetation covered the most important $(85 \%)$ part of the burned area (456 ha). The first main type is a high and dense Mediterranean shrubland (285 ha, 62\%), with plant height about $2,5 \mathrm{~m}$ height and coverage of $100 \%$. Dominant species included Juniperus phoenicea (40\%), 30\% Juniperus oxycedrus (30\%), Pistacia lentiscus (15\%), Phyllirea angustifolia $(10 \%)$, and Cistus monspeliensis in fewer amounts. This type of vegetation is referred as Shrubland 4 in the following. The second main type (104 ha, 23\%) is similar in species, but the Juneperus shrub were higher (up to $4 \mathrm{~m}$ ), and some Quercus suber were scarcely present in this area. This type of vegetation is referred as Shrubland 2.

3.2.3. Environmental Conditions. During Suartone fire, wind velocities varied between 18 to $32 \mathrm{~km} / \mathrm{h}$ with wind gusts up to $57 \mathrm{~km} / \mathrm{h}$ and wind direction ranged from $270^{\circ}$ to $290^{\circ}$. Air temperatures varied from $26^{\circ} \mathrm{C}$ (at the end of the fire) to $31^{\circ} \mathrm{C}$ during the fire event, while relative humidity of air was between $21 \%$ and $55 \%$ (at the end of the day).

\section{Fire Behavior Fuel Models}

The simulation of wildland fire necessitates determining the fuel parameters as input for the fire model and mapping the fuel complexes (or fuel types) at landscape scale for the fire simulator. Since the description of fuel properties is usually complex, researchers have summarized the physical parameters and spatial distribution of fuel in different classes
TABLE 1: The main fuel complexes identified for Corsican Island.

\begin{tabular}{lcl}
\hline $\begin{array}{l}\text { Fuel type } \\
\text { name }\end{array}$ & ID & Description \\
\hline $\begin{array}{l}\text { Alpine land } \\
\text { Mountain }\end{array}$ & 1 & Land of grass above forestry vegetation \\
land & 2 & Land of shrubs smaller than $0.6 \mathrm{~m}$ \\
Pine land 1 & 3 & Pinus laricio stand with understorey $<2 \mathrm{~m}$ \\
Pine land 2 & 4 & Pinus laricio stand with low understorey \\
Pine land 3 & 5 & Closed Pinus pinaster stand with understorey \\
Shrubland 1 & 6 & Open Pinus pinaster stand with maquis $<2 \mathrm{~m}$ \\
Oak land 1 & 7 & Closed Quercus suber stand with maquis $>2 \mathrm{~m}$ \\
Shrubland 2 & 8 & Open Quercus suber stand with maquis $<2 \mathrm{~m}$ \\
Oak land 2 & 9 & Closed Quercus ilex stand with maquis $>2 \mathrm{~m}$ \\
Shrubland 3 & 10 & Open Quercus ilex stand with maquis $<2 \mathrm{~m}$ \\
Shrubland 4 & 11 & Maquis with shrubs from $0.6 \mathrm{~m}$ to $4 \mathrm{~m}$ \\
Grassland & 12 & Herbaceous and pasture \\
Urban area & 13 & Urban area \\
\hline
\end{tabular}

also known as "fuel models" [26, 27]. A fuel model has been defined as "an identifiable association of fuel elements of distinctive species, form, size, arrangement, and continuity that will exhibit characteristic fire behavior under defined burning conditions" [28]. The most well-known fuel model is the Northern Forest Fire Laboratory system [29] that was developed for North-American vegetation. In our case, we specifically developed a new fuel type classification system to better represent the fuel characteristic of the Mediterranean ecosystems for Corsica. Other studies showed that custom fuel models provide more realistic prediction than using standard fuel model for existing fire simulator like Farsite [30]. Our classification is derived from the National Forest Inventory (IFN, http://www.ifn.fr/spip/) that was modified to aggregate vegetations exhibiting a similar response in wildfire in terms of propagation and intensity (Table 1 ). However IFN does not differentiate maquis of different height and density. As a first stage, we have thus kept one fuel type for maquis although two shrublands complexes should be considered in future: a medium height maquis for shrubs between $0.6 \mathrm{~m}$ and $2 \mathrm{~m}$ and a tall maquis for shrubs between $2 \mathrm{~m}$ and $4 \mathrm{~m}$. For the simulations of the case studies of Favone and Suartone fires, the physical characteristics of local fuel-bed maquis were determined (surface to volume ratio of particles, fuel height, heat content, etc.) from field measurements in order to be as realistic as possible.

Because not all biomass burns the same way, a fuel model is generally discriminated by size class and dead/live condition. But the fuel models may be different according to the fire model being employed for the same fuel type. For instance, in the USA, the fuel model concept was developed as a way to accommodate the input requirements of Rothermel's fire spread model [27]. In our case, the input fuel properties have to meet the requirements of the model of surface fire given in the second section. We need to consider the $1 \mathrm{hr}$ [27] size class, herbaceous, litters, and thin live particles. However, properties for other size classes 
TABLe 2: Fuel parameters for Favone and Suartone fire case studies.

\begin{tabular}{|c|c|c|c|}
\hline Case study & Variable & Favone fire & Suartone fire \\
\hline Vegetation type & & Shrubland 2 & Shrubland 4 \\
\hline \multirow{2}{*}{ Dominant species } & & Arbutus unedo & Juniperus phoenicea \\
\hline & & Erica arborea & Juniperus oxycedrus \\
\hline Height $(\mathrm{m})$ & $D_{d}$ & 2 & 2 \\
\hline \multicolumn{4}{|l|}{ Fuel load $\left(\mathrm{Mg} \cdot \mathrm{ha}^{-1}\right)$} \\
\hline $1-\mathrm{h}$ & $\sigma_{d}$ & 3.92 & 3.92 \\
\hline 10-h & Not used & 3.92 & 3.92 \\
\hline 100-h & Not used & 2.02 & 2.02 \\
\hline Litter & $\sigma_{d}$ & 5.00 & - \\
\hline Cured herbaceous & $\sigma_{d}$ & - & 0.4 \\
\hline Live leaves & $\sigma_{l}$ & 17.9 & 17.9 \\
\hline \multicolumn{4}{|l|}{ Surface to volume ratio $\left(\mathrm{m}^{-1}\right)$} \\
\hline $1-\mathrm{h}$ & $s_{d}$ & 5544 & 10200 \\
\hline Cured herbaceous & $s_{d}$ & - & 10000 \\
\hline Litter & $s_{d}$ & 5544 & - \\
\hline Live leaves & $s_{l}$ & 4766 & 10200 \\
\hline Dead heat content $\left(\mathrm{kJ} \cdot \mathrm{kg}^{-1}\right)$ & $\Delta H$ & 18620 & 18620 \\
\hline Live heat content $\left(\mathrm{kJ} \cdot \mathrm{kg}^{-1}\right)$ & Not used & 19735 & 21173 \\
\hline \multicolumn{4}{|l|}{ Fuel moisture content on dry basis $\%$} \\
\hline $1-\mathrm{h}$ & $m_{d}$ & 8 & 8 \\
\hline Cured herbaceous & $m_{d}$ & - & 8 \\
\hline Litter & $m_{d}$ & 8 & - \\
\hline Live leaves & $m_{l}$ & 100 & 39 \\
\hline Specific heat content $\left(\mathrm{J} \cdot \mathrm{kg}^{-1} \cdot \mathrm{K}^{-1}\right)$ & $c_{p d}$ & 1900 & 1900 \\
\hline Fuel density $\left(\mathrm{kg} \cdot \mathrm{m}^{-3}\right)$ & $\rho_{d}$ & 720 & 750 \\
\hline
\end{tabular}

(10-hr, 100-hr) are also provided hereafter for generality. Concerning all classes, the dry weight of fuel per unit area $\left(\mathrm{kg} \cdot \mathrm{m}^{-2}\right)$ is a required quantity. However, the behavior of a fire depends not only on the quantity of fuel available to burn but also on other structural properties of the fuel complex. The structural arrangement of fuel particles within a fuel complex is essentially defined by the packing ratio and the height of the vegetation. Then, for each fuel class, the following physical, chemical, and thermal characteristics have to be determined: density, surface areato-volume ratio, moisture content the day of the fire, low heating value, and specific heat content. Table 2 gives the input variables used for the shrublands corresponding to the Favone and Suartone case studies. The name of each variable is recalled (see the model overview in Section 2.1 and detailed presentation in appendix). These fuel models were built based on local measurement (vegetation species and height), laboratory measurement (density, surface to volume ratio, heat content, and specific heat content) and using data from previous studies conducted in North Sardinia on similar vegetation types for fuel load [30]. The moisture content of 1-h dead fuel was obtained from the literature data [30], while the moisture content of thin live particles was obtained from field measurements the day of the fire. In the simulation, we considered that the burned areas were solely covered by shrubland, since it was the main fuel type present on both sites (see Section 3).
It should be mentioned that the load of fine dead fuel is the sum of the 1-h fuel load, the litter loads and the load of the cured herbaceous. The values considered for the surface to volume ratio of fine dead fuels were $5544 \mathrm{~m}^{-1}$ for Favone fire and $10000 \mathrm{~m}^{-1}$ for Suartone fire.

\section{Results and Discussion}

As described in Section 3, for both case studies, fire fighters did suppression attacks only on the flanks of the fires and not on the head of the fires. The idea was to push the fires towards the sea. Although these attacks efficiently allowed protecting resorts and residential areas, they did not alter the rates of spread of the head fire. Obviously, the suppression attacks on the flanks allowed both fires not to enlarge drastically. But the main spreading was driven by the wind and was not modified by suppression attacks. Thus, we ran the simulation without taking into account the effect of the fire fighters on the fires. For both fires, studied areas are complex terrains typical of Corsica that modify the local wind direction. This is the reason why wind maps were calculated in order to provide more accurate wind directions and speeds over the landscape. The wind maps were obtained using a microscale wind model [31] specifically developed for the wildland fire community. The resolution of the wind maps is the same as the digital elevation model: $50 \mathrm{~m} \times 50 \mathrm{~m}$. Figure 7 presents the wind fields for Suartone case study. The figure 


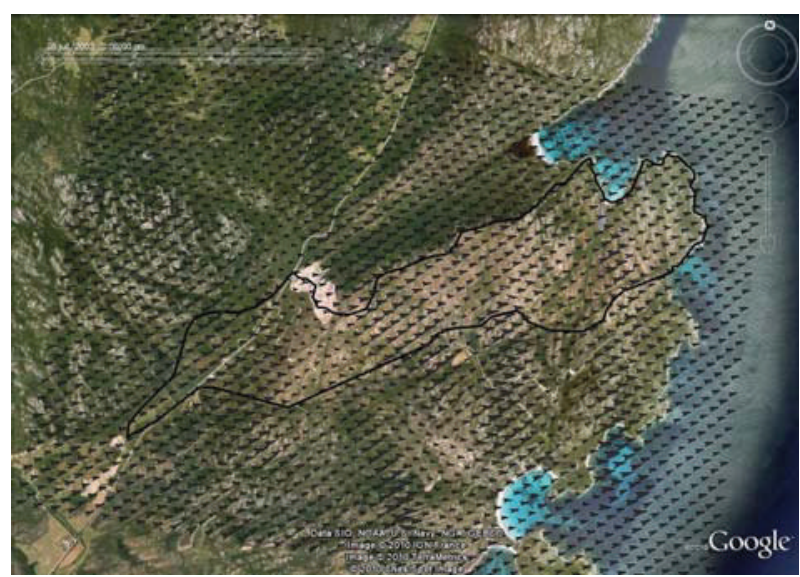

FIgURE 7: Wind fields for the case study of Suartone Fire.

clearly shows that the complexity of the terrain greatly affects the local wind that is modified in velocity and direction according to the local topography.

As detailed in Section 2, Forefire simulator is based on discrete events, and it does not necessitate any time step. The simulation were run with a quantum distance $\Delta r=8 \mathrm{~m}$ for the fire front perimeter and a quantum distance $\Delta q=0.1 \mathrm{~m}$ for the fire front advance. While thin details are taken into account with this quantum, the calculation times are less than 10 seconds and less than 30 seconds, respectively, for Favone and Suartone case studies using a $1.8 \mathrm{GHz}$ single core processor with $200 \mathrm{MO}$ of RAM. Concerning the fuel models (see Table 2), we have aggregated the 1-h fuel class and the litter to model the fine dead particles (less than $6 \mathrm{~mm}$ in diameter) for the simulation of Favone case study. To simulate Suartone fire, since the grass was fully cured, we have aggregated the 1-h fuel class and the grass in the fine dead particles. As mentioned in Section 3, we used only shrubland types 2 and 4 for the simulations of the case studies. The reasons are the following. Firstly, the vegetation type shrubland $2(20 \mathrm{ha})$ represents $69 \%$ of the burned area of Favone fire ( $29 \mathrm{ha})$, and the vegetation types shrubland 2 (104 ha) and shrubland 4 (285 ha) represent $85 \%$ of the burned area of Suartone fire ( $456 \mathrm{ha})$. Thus, the fires behavior was mainly imposed by these vegetations that cover the great part of the domains. Secondly, we have not yet acquired the input data (see Table 2) for the other vegetation types (shrubland 1 and Oakland 1) that were present in the burned areas (see Section 3). Since Corsican vegetation is very dense due to the rainfall in spring and fall, other fuel models like those given in [26] are not appropriate to model shrubland 1 and Oakland 1. Simulation results and observations are presented in Figures 8 and 9, respectively, for Favone and Suartone fire. Concerning Favone case study, the simulation was started at $15 \mathrm{~h} 00$ at the estimated ignition point and stopped at 16h15. In Figure 8, the simulated fire perimeters are plotted for a time interval of 10 minutes. We can see that both observed and simulated time of advance is in general agreement even if the simulated fire is slightly faster than actual fire (about 10 minutes). Although no observed intermediate fire perimeters are available, some

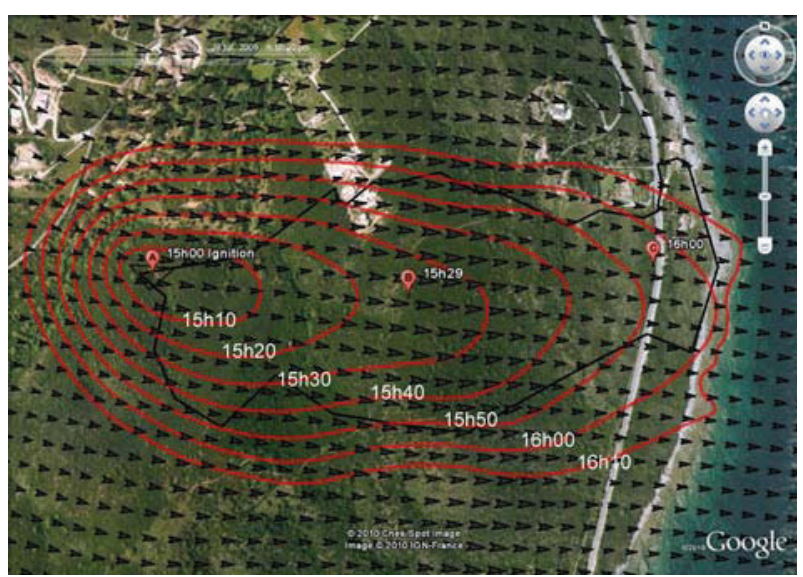

FIGURE 8: Simulated and observed intermediate time of fire advance for Favone fire with final observed perimeter and calculated wind field in black (Points A, B, and C correspond to the observed times).

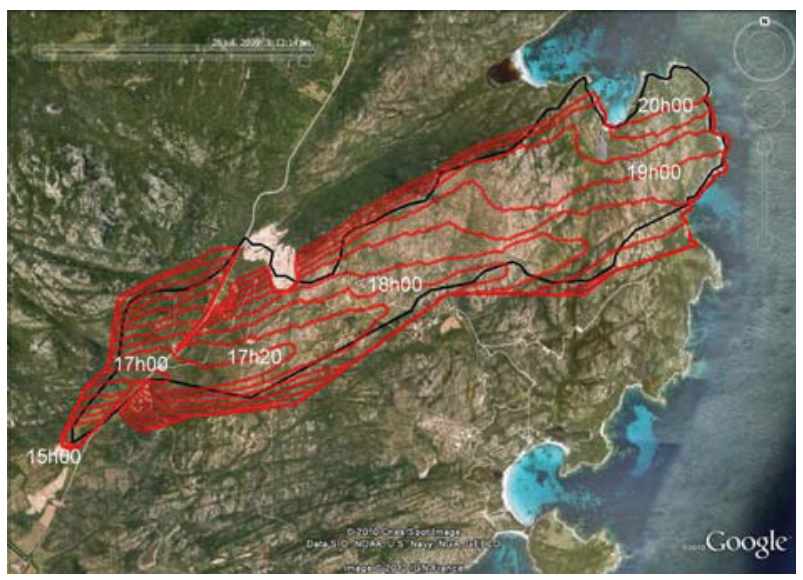

FIGURE 9: Simulated intermediate fire perimeters obtained with a nonconstant wind and observed final perimeter in black for Suartone fire.

pictures and observation confirmed that the actual fire had also a narrow head shape under downslope and wind driven conditions as predicted by the simulation. The final simulated and observed fire perimeters are also in general agreement. We can observe, however, that the simulated contour is larger than the observed one particularly at the rear and along the flanks. The reasons are the following: concerning the flanks and the rear, the firefighter attacks were not simulated; furthermore, as shown in Figures 4(a) and $4(\mathrm{~b})$, at the rear, the maquis was cleared and the vegetation was removed. The fuel map was not modified to carry out this local effect. Another reason might be a cooling effect of the wind on the fuel that is not taken into account by the fire model for counter flow fires.

Concerning Suartone fire (Figure 9), we also notice that the final simulated contour is larger than the observed one particularly at the rear and along the flanks. Since this fire was driven by a strong wind, we can thus conclude that the fire model needs some improvement for backing fires. 
However, for the rest of the prediction, the simulated results are in general agreement with the observation. In Figure 9, the simulated fire perimeters are plotted for a time interval of 20 minutes. We also observe that the fire regimes described in Section 2 are predicted by the simulation. Indeed, the acceleration of the fire under slope condition and its slowing down near Suartone village are clearly displayed by the intermediate fire perimeters.

The sensitivity of the simulator to fuel models and wind was also studied. Figure 10 displays the simulated results for constant wind $\left(25 \mathrm{~km} \mathrm{~h}^{-1}, 290^{\circ}\right)$. The comparison with Figure 9 corresponding to the simulation using a nonconstant wind field clearly exhibits that the local effects due to topography that accelerate or slow down the wind have a great influence on the rate of spread (see, e.g., time $17 \mathrm{~h} 20$ and $18 \mathrm{~h} 00$ in Figures 9 and 10). We can see that the fire perimeters distortions due to these local effects are different when the local wind (speed and direction) is different from the constant wind. These results are important in terms of fire hazard, since an increase in rate of spread leads to an increase in fire intensity hence in radiant heat flux and in acceptable safety distance.

Figure 11 displays the simulated results for a nonconstant wind field and using Anderson fuel model shrubland FM4 [26] instead of shrubland 4 . The main difference between shrubland 4 type and FM4 concerns the fuel loads and surface to volume ratios. For FM4, the 1-h fuel load and the woody fuel load were both $11.3 \mathrm{Mg} \cdot \mathrm{ha}^{-1}$. The surface to volume ratio of these two classes was, respectively, $6500 \mathrm{~m}^{-1}$ and $4900 \mathrm{~m}^{-1}$. For FM4, the 1-h fuel load is more than twice the one of shrubland 4. Figures 10 and 9 show that the best performance was obtained with simulation performed using our fuel model that is more suitable for Mediterranean vegetation. FM4 is not appropriate, because it induces an overestimation of the rate of spread (twice the rate of spread using our custom model).

\section{Conclusion}

In this paper, two wildland fire behaviour case studies were reconstructed to test the performances of a physical model of fire spread coupled with Forefire simulator. Fuel models were developed to consider typical shrubland vegetation for these Mediterranean areas. The asynchronous front tracking method used to propagate the fire front allowed simulating both case studies with a computational time significantly lower than real time (about $30 \mathrm{~s}$ simulation for 4 hours of spreading). Such simulation times opens the way for new practices in wildfire simulation, where many fighting scenarios can be tested in a short amount of time and many virtual fires can be started from a large number of possible ignition points. Simulated results were in good agreements with observation for the fire perimeter and the rates of spread in both case studies. The sensitivity of the model to wind field and fuel models was studied. It was shown that custom fuel models improve the coherency of the simulation. These fuel models are characterized by a higher live to dead fuel ratio, in comparison with the standard fuel model FM4 of Anderson [26]. Local wind field data increase the performance of the

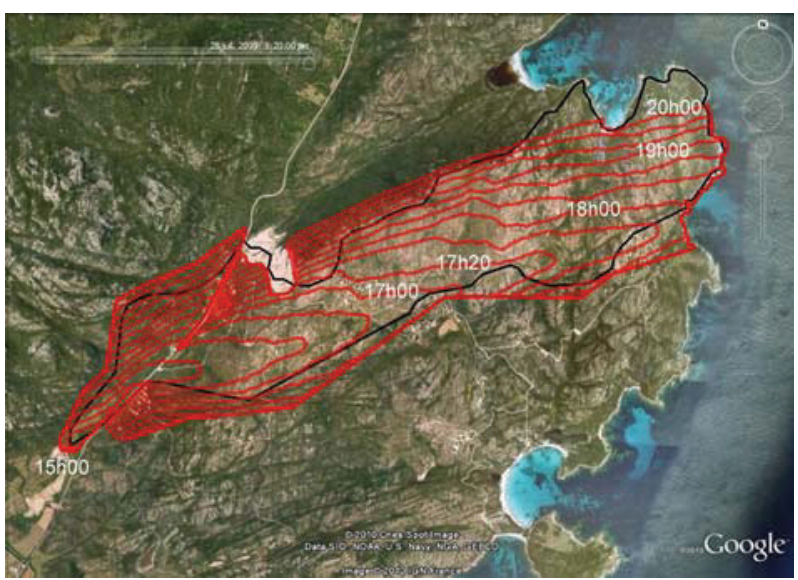

Figure 10: Simulated intermediate fire perimeters obtained with a constant wind $\left(25 \mathrm{~km} \mathrm{~h}^{-1}, 290^{\circ}\right)$ and observed final perimeter in black for Suartone fire.

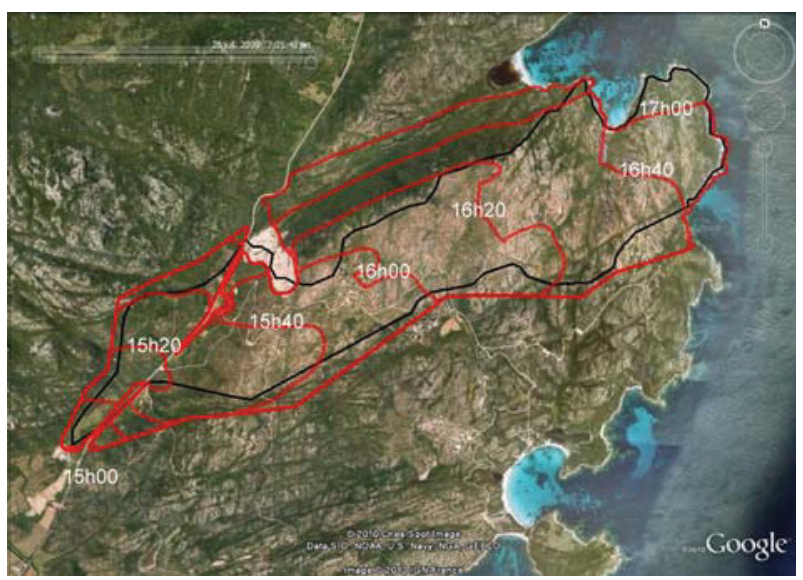

FIGURE 11: Simulated intermediate fire perimeters obtained with a non constant wind and Anderson [26] fuel model FM4 for Suartone fire. Observed final perimeter is in black.

simulation by depicting the local increase in rate of spread. However, two case studies are not sufficient to validate the simulator. Information derived from databases of actual fires that occurred in Mediterranean areas will be used to provide an extensive calibration and validation of the simulator. Enhancements of the simulation system are planned in order to model the cooling effect of the wind during counterflow fires and to take into account the effects of the relative humidity on the fire dynamics during the night.

\section{Appendix}

\section{A. Detailed Presentation of the Fire Model}

This appendix presents the derivation of (1) to (4d). Since the details of this derivation were already provided in [12], only the most relevant steps are given.

A.1. Derivation of (1), (3a), (4a), and (4b). Equation (1) was derived from the mass balance and from the composition of the velocity in the flame. 
Mass Balance. Along one meter of a fire front without wind, the flow rate of pyrolysis gases is given by $L \dot{\sigma}_{d}$, where $L$ is the fire front depth (see Figure 1) and $\dot{\sigma}_{d}$ is the mass loss rate. Assuming that the air enters the flame according to the stoichiometric proportion $s_{t}$, it leads to a flow rate $s_{t} L \dot{\sigma}_{d}$. The mass flow rate at mid-height of the flame is given by

$$
\rho_{f} \frac{L}{2} \vec{u} \cdot \vec{N}=\rho_{f} \frac{L}{2} \cos \alpha u
$$

where $\rho_{f}$ is the density of the flame gases, $\vec{u}$ is the upward velocity into the flame, $\alpha$ is the slope angle, and $\vec{N}$ is the normal to the ground (see Figure 1). The mass balance gives

$$
\rho_{f} \frac{L}{2} \cos \alpha u=L \dot{\sigma}_{d}+s_{t} L \dot{\sigma}_{d}
$$

This expression yields to

$$
u=\frac{u_{0}}{\cos \alpha}
$$

with

$$
u_{0}=\frac{2\left(s_{t}+1\right)}{\rho_{f}} \dot{\sigma}_{d}
$$

where $u_{0}$ stands for the upward velocity of the combustion gases for no slope.

By using the quasi-isobaric assumption for the flame gases,

$$
\rho_{f} T_{f}=\rho_{a} T_{a}
$$

and the Anderson [23] model for the residence time of fine dead particles, $\tau$,

$$
\tau=\tau_{0} / s_{d},
$$

with $\tau_{0}=75590 \mathrm{~s} \cdot \mathrm{m}^{-1}$ and $s_{d}$ the surface to volume ratio of the dead fuel, (A.4) becomes (3a) with (4a) and (4b), where $D_{d}$ is the depth of the vegetation and $\beta_{d}$ is the packing ratio of the fuel. The coefficient $v$ indicates whether all the vegetation is burning ( $\left.v=s_{d} D_{d} \beta_{d} / 4\right)$ or a height corresponding to the optical length $(v=1)$.

Velocity Composition and Flame Tilt Angle. We assume that the tilt of the flame is given by the composition of the previous calculated upward velocity $\vec{u}$ and the wind field velocity $\vec{U}$. Thus, the gas velocity in the flame is given by $\vec{V}=\vec{U}+\vec{u}$, and the normal component of the velocity field that tilts the flame (see Figure 1) is given by

$$
\vec{V}_{\text {normal }}=U \cos \psi \vec{n}+u(\cos \alpha \vec{N}+\sin \alpha \cos \phi \vec{n}),
$$

where $\vec{n}$ is the unit vector normal to the fire front, $\phi$ is the angle between the unit vector normal to the fire front and the unit ground slope vector, and $\psi$ is the angle between the unit vector normal to the fire front and the wind velocity vector, $\vec{U}$ see [12].The resulting tilt angle is given by

$$
\tan \gamma=\frac{u \sin \alpha \cos \phi+U \cos \psi}{u \cos \alpha}
$$

that is, (1).
A.2. Derivation of (4d). Equation (4d) was derived from the thermal balance written for one meter of the flame front

$$
\rho_{f} c_{p a} u \frac{L}{2} T_{f} \cos \alpha=\left(s_{t}+1\right) L c_{p a} \dot{\sigma}_{d} T_{a}+\left(1-\chi_{0}\right) Q
$$

where $c_{p g}$ is the specific heat content of air at $1273 \mathrm{~K}, \chi_{0}$ represents the radiant fraction of the rate of heat released within the flame $Q$, and $T_{a}$ is the ambient temperature. Substituting (A.2) in (A.9) and using $Q=\Delta H L \dot{\sigma}_{d}$, where $\Delta H$ is the net heat of combustion of the gases, we obtain the flame temperature; (see (4d)).

A.3. Derivation of (2), (2a), (2b), (3b), (3c), and (4c) Thermal Balance in the Unburned Fuel. Equations (2), (2a), and (2b) were derived from the thermal balance written in the unburned fuel ahead of the flame front

$$
\sigma_{d} c_{p d} \frac{d T_{d}}{d t}=\phi_{B}+v \phi_{F}-\Delta h \frac{d \sigma_{H_{2} O}}{d t}
$$

where $\phi_{B}$ and $\phi_{F}$ represent, respectively, the radiant heat flux incoming from the embers and from the flame, $\sigma_{d}$ is the fuel load, $c_{p d}$ is the specific heat content of the fuel, $\Delta h$ is the latent heat of vaporization of water $(\Delta h=2.25 \times$ $10^{3} \mathrm{~kJ} / \mathrm{kg}$ ), and $\sigma_{\mathrm{H}_{2} \mathrm{O}}$ represents the water load. The fraction of the flame radiation absorbed by the fuel is denoted by $v$ (see Section A.1). Let $\delta$ be the optical length through the vegetation given by $\delta=4 /\left(s_{d} \beta_{d}\right)$, and the integration of (A.10) gives:

$$
R \sigma_{d}\left[c_{p d}\left(T_{i g}-T_{a}\right)+m_{d} \Delta h\right]=\int_{0}^{\delta} \phi_{B} d x+v \int_{0}^{\ell \sin \gamma} \phi_{F} d x,
$$

where $T_{i g}$ is the temperature of ignition, $m_{d}$ is the fuel moisture content on dry basis, $\ell$ is the flame length, and $R$ is the rate of spread. The submodels for radiation $\phi_{B}$ and $\phi_{F}$ are detailed in [12] and are not provided here. After integration, we obtain

$$
\begin{gathered}
\int_{0}^{\delta} \phi_{B} d x=B T_{B}^{4} D_{d}, \\
\int_{0}^{\ell \sin \gamma} \phi_{F} d x=\frac{\varepsilon_{f}}{2} B T_{f}^{4} \ell(1+\sin \gamma-\cos \gamma),
\end{gathered}
$$

where $B$ is the Stefan-Boltzman constant, $T_{B}$ is the temperature of embers, and $\varepsilon_{f}$ is the flame emissivity. Equation (A.11) gives

$$
R=\frac{D_{d}}{\sigma_{d}} \frac{B T_{B}^{4}}{\left(c_{p d} \Delta T+m_{d} \Delta h\right)}+v \frac{\varepsilon_{f} B T_{f}^{4} \ell(1+\sin \gamma-\cos \gamma)}{2 \sigma_{d}\left(c_{p d} \Delta T+m_{d} \Delta h\right)}
$$

where $\Delta T=T_{i g}-T_{a}$. This equation can thus be written as (2) with (2a) and

$$
R_{F}=v \frac{\varepsilon_{f} B T_{f}^{4} \ell(1+\sin \gamma-\cos \gamma)}{2 \sigma_{d}\left(c_{p d} \Delta T+m_{d} \Delta h\right)} .
$$


We will now modify relation (A.15) in order to show that it corresponds to $(2 \mathrm{~b})$. First, since half the flame is radiating towards the unburned fuel, we can write that

$$
\varepsilon_{f} B T_{f}^{4} \ell=\frac{\chi}{2} Q=\frac{\chi}{2} \Delta H \dot{\sigma}_{d} L .
$$

Since $\dot{\sigma}=\sigma / \tau$ and $L=R \tau$, (A.16) becomes

$$
\varepsilon_{f} B T_{f}^{4} \ell=\frac{\chi}{2} \Delta H \sigma_{d} R
$$

Substituting (A.17) into (A.15) leads to

$$
R_{F}=v \frac{\chi \Delta H}{4\left(c_{p d} \Delta T+m_{d} \Delta h\right)} R(1+\sin \gamma-\cos \gamma)
$$

McCaffrey's correlation [32] indicates that the radiant fraction is constant as long as the flame remains relatively thin and then decreases slowly with an increasing flame thickness. This assumption was used in [12] and led to the following relationship for $\chi$ to establish its variation with the surface to volume ratio of the flame

$$
\chi=\frac{\chi_{0}}{1+(R \cos \gamma) / r_{0}},
$$

with (3b) and $\chi_{0}=0.3[33]$.

Substituting (A.19) in (A.18) leads to

$$
R_{F}=v \frac{\chi_{0} \Delta H}{4\left(c_{p d} \Delta T+m_{d} \Delta h\right)} R \frac{1+\sin \gamma-\cos \gamma}{1+(R \cos \gamma) / r_{0}},
$$

which becomes (2b) with (3c) and (4c), and $r_{00}$ was determined by fitting the predicted and observed rate of spread for several test fires conducted across different fuel and fuel loads. We obtained $r_{00}=2.5 \times 10^{-5} \mathrm{~m} \cdot \mathrm{s}^{-1} \cdot r_{00}$ that can be considered as the only empirical parameters of the model.

\section{Nomenclature}

$A_{0}$ : Function of variables

$B$ : Stefan-Boltzman constant

$c_{p}$ : Specific heat

$D$ : Depth of the vegetation

$l:$ Flame length

$L:$ Fire front depth

$m$ : Moisture content on dry basis

$\vec{n}$ : Unit vector normal to the fire front

$\vec{N}$ : Unit vector normal to the ground

$r_{00}$ : Empirical constant

Q: Rate of heat released within the flame

$R:$ Rate of spread of the fire front

$R_{B}$ : Contributions on rate of spread due to embers

$R_{F}$ : Contributions on rate of spread due to the flame $s: \quad$ Surface to volume ratio of particles

$s_{t}$ : Stoichiometric mass based air/fuel ratio

T: Temperature

$\vec{u}$ : Upward velocity vector in the flame without wind

$u_{0}$ : Value of the upward velocity in the flame without wind and without slope

$u_{00}$ : Function of variables

$\vec{U}$ : Wind velocity

$\vec{V}$ : Composition of wind velocity and upward velocity in the flame.

\section{Greek Symbols}

$\alpha$ : Slope angle

$\beta: \quad$ Packing ratio of the vegetation

$\chi$ : Function of variables

$\chi_{0}$ : Radiant fraction of the rate of heat release within the flame

$\delta$ : Optical length

$\varepsilon:$ Emissivity

$\phi$ : Angle between the unit vector normal to the fire front and the unit ground slope vector

$\phi_{B}$ : Radiant heat flux incoming from the embers

$\phi_{F}$ : Radiant heat flux incoming from the flame

$\gamma$ : Flame tilt angle

$\rho$ : Density

$\sigma: \quad$ Load

$\tau$ : $\quad$ Residence time of fine dead particles

$\tau_{0}:$ Empirical constant

$v$ : Fraction of the vegetation height involved in fire

$\psi$ : Angle between the unit vector normal to the fire front and the wind velocity vector

$\Delta H$ : Net heat of combustion

$\Delta h$ : Latent heat of vaporization of water $2.25 \times 10^{3} \mathrm{~kJ} / \mathrm{kg}$

$\Delta T: T_{i g}-T_{a}$.

\section{Subscripts}
a: ambient air
B: Embers
$d$ : Dead fuel
$f$ : Flame
ig: Ignition.

\section{Acknowledgments}

This work was carried out in the scope of project PROTERINA-C supported by the EU under the Thematic 3 of the Operational Program Italia/France Maritime 20072013, Contract no. G25I08000120007. The authors wish to thank Philippe Caramelle of the Office National des forêt, Jean-Yves Duret of the Conseil général de la Corse du Sud, Commandant Dominique Canale, Commandant André Giorgi, and Major Jean-Louis Nicolai of Service Départemental d'Incendie et de Secours de la Corse du Sud 
for their help in reconstructing the case studies. Simulation code was developed in the frame of the ANR IDEA Project (no. ANR-09-COSI-006).

\section{References}

[1] W. Mell, M. A. Jenkins, J. Gould, and P. Cheney, "A physicsbased approach to modelling grassland fires," International Journal of Wildland Fire, vol. 16, no. 1, pp. 1-22, 2007.

[2] X. Zhou, S. Mahalingam, and D. Weise, "Experimental study and large eddy simulation of effect of terrain slope on marginal burning in shrub fuel beds," in the 31st International Symposium on Combustion, pp. 2547-2555, August 2006.

[3] J. H. Balbi, J. L. Rossi, T. Marcelli, and P. A. Santoni, "A 3D physical real-time model of surface fires across fuel beds," Combustion Science and Technology, vol. 179, no. 12, pp. 25112537, 2007.

[4] D. Morvan, S. Méradji, and G. Accary, "Physical modelling of fire spread in Grasslands," Fire Safety Journal, vol. 44, no. 1, pp. 50-61, 2009.

[5] P. Fiorucci, F. Gaetani, and R. Minciardi, "Development and application of a system for dynamic wildfire risk assessment in Italy," Environmental Modelling and Software, vol. 23, no. 6, pp. 690-702, 2008.

[6] E. Pastor, L. Zárate, E. Planas, and J. Arnaldos, "Mathematical models and calculation systems for the study of wildland fire behaviour," Progress in Energy and Combustion Science, vol. 29, no. 2, pp. 139-153, 2003.

[7] A. L. Sullivan, "Wildland surface fire spread modelling, 19902007. 3: Simulation and mathematical analogue models," International Journal of Wildland Fire, vol. 18, pp. 387-403, 2009.

[8] A. G. McArthur, Weather and grassland fire behavior, Commonwealth Department of National Development, Forestry and Timber Bureau Leaflet 100, Canberra, Australia, 1966.

[9] R. C. Rothermel, "A mathematical model for predicting fire spread in wildland fuels," Research Paper INT-115, USDA Forest Service, 1972.

[10] F. A. Albini, "A model for fire spread in wildland fuels by radiation," Combustion Science and Technology, vol. 42, pp. 229-258, 1985.

[11] R. Linn, J. Reisner, J. J. Colman, and J. Winterkamp, “Studying wildfire behavior using FIRETEC," International Journal of Wildland Fire, vol. 11, no. 3-4, pp. 233-246, 2002.

[12] J. H. Balbi, F. Morandini, X. Silvani, J. B. Filippi, and F. Rinieri, "A physical model for wildland fires," Combustion and Flame, vol. 156, no. 12, pp. 2217-2230, 2009.

[13] J. B. Filippi, F. Morandini, J. H. Balbi, and D. R. Hill, "Discrete event front-tracking simulation of a physical firespread model," Simulation, vol. 86, no. 10, pp. 629-644, 2010.

[14] P. A. Santoni, A. Simeoni, J. L. Rossi et al., "Instrumentation of wildland fire: characterisation of a fire spreading through a Mediterranean shrub," Fire Safety Journal, vol. 41, no. 3, pp. 171-184, 2006.

[15] M. E. Alexander and S. W. Taylor, "Wildland fire behavior case studies and the 1938 honey fire controversy," Fire Management Today, vol. 70, no. 1, pp. 15-25, 2010.

[16] M. A. Finney, "FARSITE: fire area simulator-model development and evaluation," Research Paper RMRS-RP-4, USDA Forest Service, Rocky Mountain Research Station, Fort Collins, Colo, USA, 1998.

[17] J. R. Coleman and A. L. Sullivan, "A real-time computer application for the prediction of fire spread across the
Australian landscape," Simulation, vol. 67, no. 4, pp. 230-240, 1996.

[18] A. G. McArthur, Fire behaviour in eucalypt forests, Commonwealth Department of National Development, Forestry and Timber Bureau Leaflet 107, Canberra, Australia, 1967.

[19] N. P. Cheney, J. S. Gould, and W. R. Catchpole, "Prediction of fire spread in grasslands," International Journal of Wildland Fire, vol. 8, no. 1, pp. 1-13, 1998.

[20] CWFGM Steering Committee, Prometheus User Manual v. 3.0.1, Canadian Forest Service, 2004.

[21] Forestry Canada Fire Danger Group, "Development and structure of the Canadian Forest Fire Behavior Prediction System," Information Report ST-X-3, Forestry Canada Science and Sustainable Development Directorate, Ottawa, Canada, 1992.

[22] G. D. Richards, "A general mathematical framework for modeling twodimensional wildland fire spread," International Journal of Wildland Fire, vol. 5, pp. 63-72, 1995.

[23] H. E. Anderson, "Heat transfer and fire spread," Tech. Rep. INT-69, USDA Forest Service, Intermountain Forest and Range Experiment Station, Ogden, Utah, USA, 1969.

[24] B. P. Zeigler, "Hierarchical, modular discrete-event modelling in an object-oriented environment," Simulation, vol. 49, no. 5, pp. 219-230, 1987.

[25] C. E. Van Wagner, "Conditions for the start and spread of crown fire," Canadian Journal of Forest Research, vol. 7, no. 1, pp. 23-34, 1977.

[26] H. E. Anderson, "Aids to determining fuels models for estimating fire behavior," Tech. Rep. INT-122, USDA Forest Service, Ogden, Utah, USA, 1982.

[27] R. Burgan and R. C. Rothermel, "BEHAVE: fire behaviour prediction and fuel modelling system-FUEL subsystem," Tech. Rep. INT-167, USDA Forest Service, 1984.

[28] D. F. Merrill and M. E. Alexander, Glossary of Forest Fire Management Terms, National Research Council of Canada, Committee for Forest Fire Management, Ottawa, Canada, 1987.

[29] F. A. Albini, "Estimating wildfire behaviour and effects," Tech. Rep. INT-30, USDA Forest Service, Ogden, Utah, USA, 1976.

[30] B. Arca, P. Duce, M. Laconi, G. Pellizzaro, M. Salis, and D. Spano, "Evaluation of FARSITE simulator in Mediterranean maquis," International Journal of Wildland Fire, vol. 16, no. 5, pp. 563-572, 2007.

[31] J. Forthofer, K. Shannon, and B. Butler, "Simulating diurnally driven slope winds with WindNinja," in Proceedings of 8th Symposium on Fire and Forest Meteorological Society, 2009.

[32] B. J. McCaffrey, "Some measurements of the radiative power output of diffusion flame," in the Western States Meeting of the Combustion Institute (WSS/CI '81), Pullmann, Wash, USA, 1981.

[33] J. G. Quintiere, Principles of Fire Behavior, Delmar Publishers, Albany, NY, USA, 1997. 

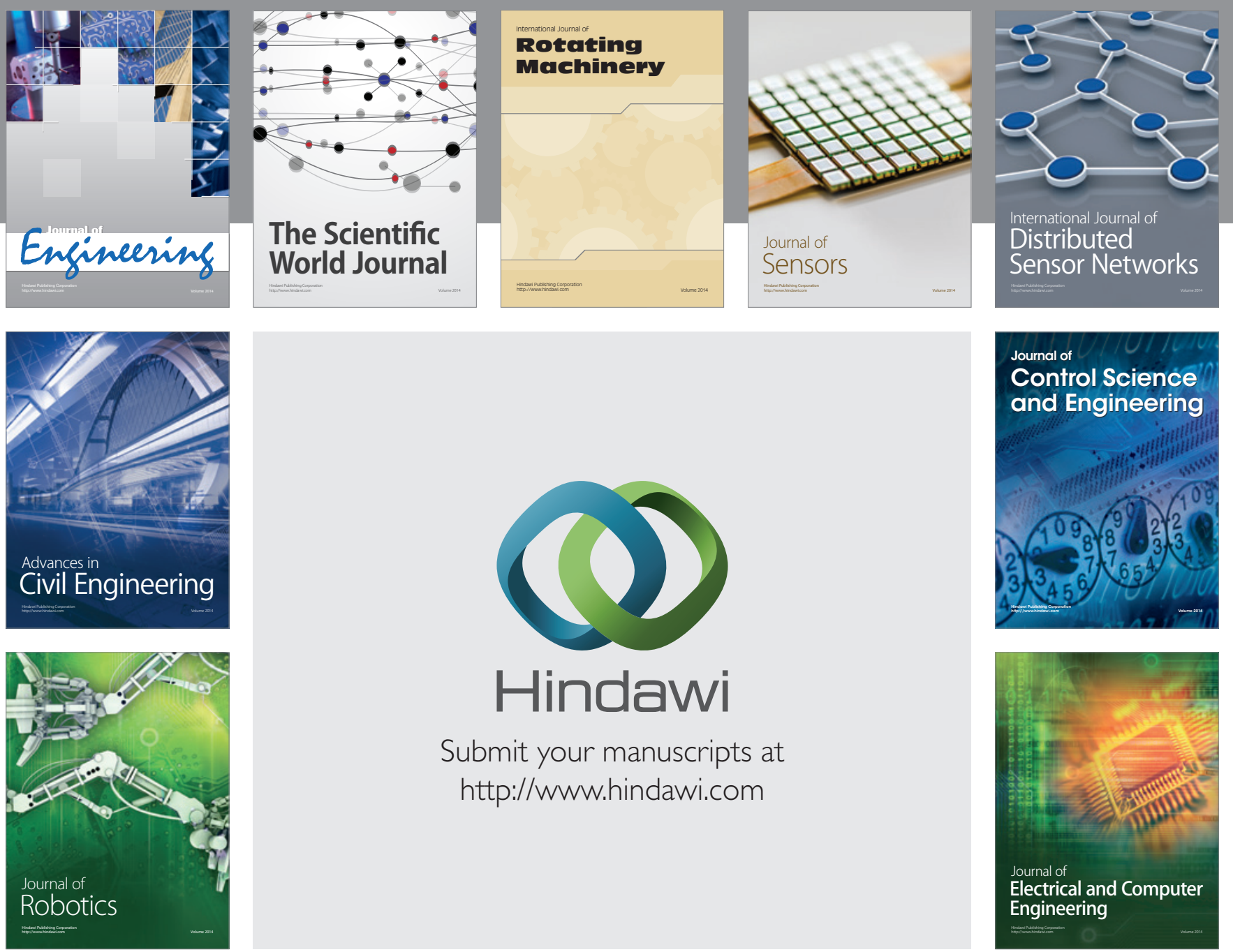

Submit your manuscripts at

http://www.hindawi.com
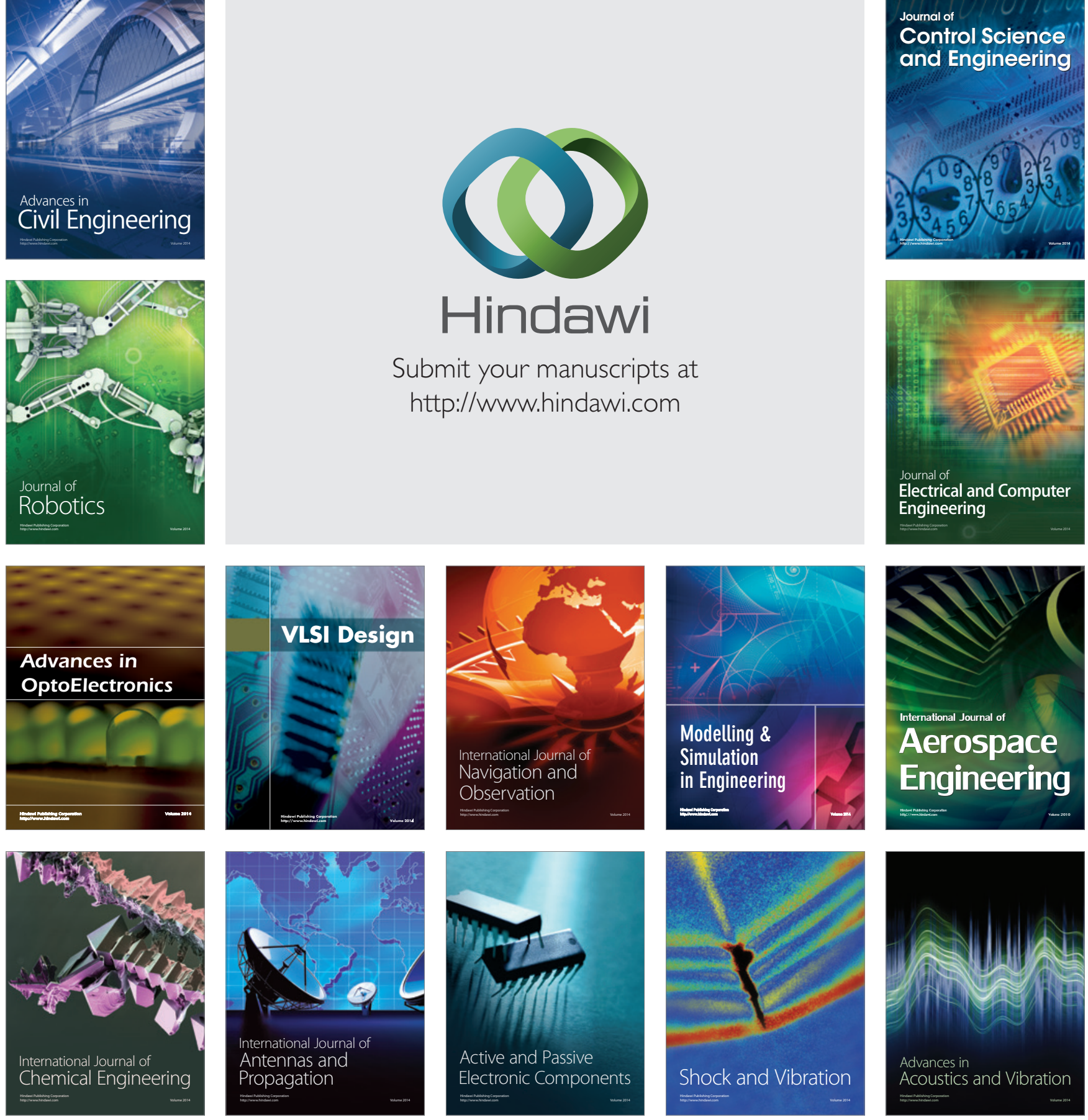